\section{Endocrinopathy in polyneuropathy, organomegaly, endocrinopathy, monoclonal gammopathy and skin changes syndrome}

\author{
Manhora Kenchaiah,1 Devish Sennik, ${ }^{1}$ \\ Hisham Elhag Ali, ${ }^{1}$ Nigel Beharry, ${ }^{2}$ \\ Philp Wilson, ${ }^{3}$ Chistopher Anderson, 4 \\ Steven Schey, 5 Gul Bano ${ }^{6}$ \\ 1 Department of Diabetes and \\ Endocrinology, St. George's Healthcare \\ NHS Trust; ${ }^{2}$ Department of Radiology, St. \\ George's Healthcare NHS Trust; \\ 3Department of Cellular Pathology, St. \\ George's Healthcare NHS Trust; \\ 4Deparment of Urology, St. George's \\ Healthcare NHS Trust; ${ }^{5}$ Department of \\ Haematological Medicine, King's College \\ London, Denmark Hill; 'Cellular and \\ Molecular Medicine, St George's \\ University of London, UK
}

\section{Abstract}

Polyneuropathy, organomegaly, endocrinopathy, monoclonal gammopathy and skin changes (POEMS) syndrome is a rare paraneoplastic syndrome due to underlying plasma cell disorder. It belongs to group of plasma cell dyscrasias such as multiple myeloma, waldenstrom's macroglobulinemia, castleman disease and monoclonal gammopathy of undetermined significance. The term POEMS syndrome was first coined in 1980 by Bardwick. In the last 10 years clinical criteria to diagnose POEMS syndrome have been elaborated to avoid overlap with other haematological disorders. Due to disease rarity there is very few case series and case reports described in literature. This is a haematological disease which frequently presents with peripheral neuropathy but endocrine dysfunction can be a presenting or an associated feature. We report two cases of POEMS syndrome who presented with endocrinopathy as a predominant feature with literature review of this syndrome.

\section{Introduction}

Polyneuropathy, organomegaly, endocrinopathy, monoclonal gammopathy, and skin changes (POEMS) syndrome is a rare medical syndrome. It begins in middle age and the average age at onset is around 50. It affects up to twice as many men as women. ${ }^{1}$ Endocrinopathy can be the main presenting feature of POEMS syndrome. Most information regarding endocrinopathy in POEMS syndrome has come from isolated case reports and small case series. Specific endocrine abnormalities associated with POEMS syndrome vary from case to case. The cause of endocrinopathy in this disorder is unknown. Involved endocrine organs have been found to be structurally normal suggesting that it may be a functional problem. ${ }^{2}$ Hormonal disorders associated with POEMS syndrome include hypogonadism, diabetes mellitus, hypothyroidism, hyperprolactenemia, Acromegaly, adrenal insufficiency, gynaecomastia in men and hypoparathyroidsm. ${ }^{3,4}$

\section{Case Report \#1}

A 56 year old Caucasian male was referred to Urology with history of hematuria. He was recently diagnosed with Type 2 Diabetes Mellitus and was treated with oral hypoglycemics. He had history of back ache and pain in his feet for the last 2 years. The pain in his feet was burning in sensation and interfered with his sleep. He had undergone partial thyroidectomy 30 years ago for a large goitre. His imaging showed a renal mass in the lower pole of left kidney and an incidental $5 \mathrm{~cm}$ left adrenal mass with enlarged lymphnodes (Figure 1). He was referred to Endocrinologist for evaluation of the left adrenal mass. On examination he was noticed to have hyperpigmented skin on his abdomen (Figure 2) but no haemagiomas were seen. His blood pressure was 140/80 $\mathrm{mmHg}$. His 24 hours urinary metanephrines were markedly high. His laboratory data is shown in Tables 1 and 2. His MIBG Scan showed a focus of increased tracer uptake lying in the left upper quadrant consistent with left sided pheochromocytoma (Figure 3 ). He had left nephrectomy and adrenalectomy after appropriate preparation. The left renal mass on histology was a myelofibroblastic tumour (Figure 4) and the left adrenal mass was a pheochromocytoma with ganglioneuromatous areas (Figure 5). The removed lymph nodes showed features typical of Castlemans disease of the plasma cell form (Figure 6). His diabetes resolved after removal of pheochromocytoma and he has not required any treatment for diabetes for last 2 years. He had MRI of his spine that demonstrated marked thickening of the nerve roots within the foramina of the right L3/4 and L4/5 levels and left L3/4 levels. There was also extensive plaque like thickening in the soft tissue, at the back, with prominent vessels, and local subcutaneous changes dorsally. There were no osteolytic bone lesions. His nerve conduction study showed axonal neuropathy. He had further work up for Castleman's disease including pro-
Correspondence: Gul Bano, Thomas Addison Unit, St George's Hospital, Blackshaw Road, SW17 0QT, UK.

Tel. +44.020.87251027 - Fax: +44.020 .87250240$

E-mail: gbano@sgul.ac.uk

Key words: endocrinopathy, POEMS syndrome.

Contributions: MK, DS, HAB, participated in working up, management and investigations of the patients, they also helped in drafting the article; NB, helped with imaging and reporting the images; PW, helped interpretation of histology and diagnosis of Castleman's disease; CA, operated on the patients and helped obtain tissue for the diagnosis; SS, treated the patient with Castleman's disease and helped with staging of disease; GB, contributed to conception, acquisition of data and interpretation, revised the document for intellectual interpretation and approved the version to be published.

Conflict of interests: the authors report no conflict of interests.

Received for publication: 28 September 2012. Revision received: 7 November 2012

Accepted for publication: 12 November 2012.

This work is licensed under a Creative Commons Attribution NonCommercial 3.0 License (CC BYNC 3.0)

(C) Copyright M. Kenchaiah et al., 2013

Licensee PAGEPress, Italy

Endocrinology Studies 2013; 3:e1

doi:10.4081/es.2013.e1

tein studies, bone marrow aspirate and Trephine and CT scan of chest and abdomen. His investigations showed IgG lambda paraproteinemia of $9 \mathrm{gms} / \mathrm{L}$ with normal IgA and IgM levels. His full blood count white cell differential, haemoglobin and platelet counts were within the normal range. His bone marrow aspirate was hypocellular with no abnormal infiltrate; cytogenetics demonstrated a normal karyotype: $46, \mathrm{XY}$ with no clonal abnormalities detected. Fifteen cells were analysed. Histology showed a fragmented and hypocellular $(25-30 \%)$ bone marrow trephine of adequate length. All three cell lines are present with tri-lineage haematopoesis and good maturation. Immunohistochemical staining showed a mild plasma cell infiltratrate $(<5 \%$ of TNC) with no light chain restriction. There were also scattered B- and T-cells as part of the normal marrow components. No amyloid was seen on congo red staining. Reticulin staining was increased (grade 1-2). The appearances were non-diagnostic and were those of a reactive bone marrow.

He was treated with Rituximab $375 \mathrm{mg} / \mathrm{m}^{2}$ on Day 1, 8, 15 and 22, further Rituximab 100 mg a day on Day 1-28, Thalidomide $0.75 \mathrm{mg} / \mathrm{kg}$ 
orally on Day 1-7 and Prednisolone for Castleman disease. A year later he presented with enlarging thyroid with symptoms of tracheal compression and required total thyroidectomy. He developed hypothyroidism and hypparathyroidism after the surgery and is now on replacement.

\section{Case Report \#2}

A 73 year man presented with fatigue and severe leg pains of nearly 6 months duration. He had history of Acromegaly diagnosed at the age of 51 years. This was treated with transsphenoidal surgery. He did not receive radiotherapy. His acromegaly was not well controlled so he had treatment with somatostatin analogue and this resulted in remission of his acromegaly. His bilateral leg pain was found to be due to Axonal neuropathy. He was treated with amityrptiline and then pregabalin. He had history of treatment for Pulmonary Tuberculosis in the past. During his follow-up he was found to have mild anaemia. He had high total protein and an elevated ESR. He had Bone aspiration. He had elevated IgM and IgA kappa chain paraproteins and diagnosis of monoclonal gammopathy of unknown significance (MGUS) was made by the haematologist. He has been recently diagnosed with primary Hypothyroidism due to hashimotos thyroiditis. He had no skin pigmentation or haemagiomas. His vascular endothelial growth factor (VEGF) levels were normal at $91 \mathrm{pg} / \mathrm{mL}$ (normal less than 771).

\section{Discussion}

POEMS syndrome is rare and research in last 10 years has provided more insight in to this multisystem disorder. There are now clear guidelines to diagnose POEMS syndrome; these include major and minor criteria. In order to make the diagnosis of POEMS syndrome two major and a minor criteria are essential to differentiate this from other haematological conditions like Myeloma, primary systemic amyloidosis and waldenstrom disease. The major criteria include polyneuropathy (typically demyelinating), monoclonal plasma cell proliferative disorder, castleman disease, sclerotic bone disease and elevated VEGF. The minor criteria include organomegaly, extravascular volume overload (pleural effusion, ascites, edema), endocrinopathy, polycythemia, papilledema and skin changes (hyperpigmentation, hypertrichosis, plethora, acrocyanosis, flushing, white nails). Some may have associated symtpoms and signs like clubbing, weight loss, hyperhidrosis and restrictive lung disease..$^{5}$

The endocrinopathies are being recognised more as a part of this syndrome. Thus prevalence of endocrinopathy depends on the timing of the case series of POEMS syndrome. The exact pathogenesis of endocrinopathy is unknown. Initially it was suggested that high prevalence of gamma light chains had a key role in pathogenesis but later studies that included histopathological review of affected organs did not support this hypothesis. No circulating antibodies against the hormone or the hormonal receptor have been found. ${ }^{2}$ Loss of balance between proinflammatory and antiinflammatory cytokines has been postulated by some research group. ${ }^{6}$ Recently role of vascular endothelial growth factor (VEGF) on neovascularisation and vessel permeability was

Table 1. Clinical characteristics.

\begin{tabular}{lcc} 
& Case 1 & Case 2 \\
Age & 56 & 72 \\
Sex & Male & Male \\
\hline Ethnic origin & Caucasian & Caucasian \\
Criteria for the diagnosis of POEMS syndrome & 4 & 3 \\
\hline Polyneuropathy & yes & yes \\
Skin hyperpigmentation & yes & no \\
\hline Castleman disease & yes & No \\
Paraproteinemia & no & Yes \\
\hline Endocrinopathy & IgG kappa & Yes \\
Adrenal & yes & No \\
\hline Pituitary & Pheochromocytoma & Acromegaly \\
Thyroid & No & Hypothyroidism \\
\hline Diabetes & Yoitre with retrosternal extension & No \\
Albumin & $42 \mathrm{~g} / \mathrm{dL}(35-48)$ & $37 \mathrm{~g} / \mathrm{dL}(35-48)$ \\
\hline Creatinine & $127 \mathrm{umol} / \mathrm{L}(60-110)$ & $105 \mathrm{umol} / \mathrm{L}(60-110)$ \\
Hemoglobin & $12.4 \mathrm{~g} / \mathrm{dL}(13-18)$ & $12.5 \mathrm{~g} / \mathrm{dL}(13-15)$ \\
\hline ESR & $81 \mathrm{~mm} / \mathrm{h}(1-20)$ & $56 \mathrm{~mm} / \mathrm{h}(1-20)$ \\
\hline
\end{tabular}

POEMS, polyneuropathy, organomegaly, endocrinopathy, monoclonal gammopathy and skin changes; ESR, erythrocyte sedimentation rate.

Table 2. Laboratory data.

Adrenal

24 hours urine

Noradrenaline total urine $1663 \mathrm{nmol} / 24 \mathrm{H}(0-500)$

Adrenaline total urine $729 \mathrm{nmol} / 24 \mathrm{H}(0-100)$

Dopamine total urine $4739 \mathrm{nmol} / 24 \mathrm{H}(0-3000)$

Normetadrenaline total urine $16.48 \mathrm{umol} / 24 \mathrm{H}(0-2.5)$

Metadrenaline $21.03 \mathrm{umol} / 24 \mathrm{H}(0-1.2)$

Acromegaly treated with transhenoidal surgery in 1982

IGF-1 $21.1 \mathrm{nmol} / \mathrm{L}$ (7.2-21.6) on somatostatin analogue

\begin{tabular}{lll}
\hline Free T4 & $11.9 \mathrm{pmol} / \mathrm{L}(10-23)$ on thyroxine $150 \mathrm{mcg}$ & $14.4 \mathrm{pmol} / \mathrm{L}(11-23)$ on thyroxine $75 \mathrm{mcg}$ \\
Testosterone & $17.3 \mathrm{nmol} / \mathrm{L}(9.9-27.8)$ & $12.5 \mathrm{nmol} / \mathrm{L}(9.9-27.8)$ \\
\hline FSH & $12.3 \mathrm{IU} / \mathrm{L}(1-10)$ & $7.0 \mathrm{IU} / \mathrm{L}(1-10)$ \\
LH & $8.4 \mathrm{IU} / \mathrm{L}(1-9)$ & $1.4 \mathrm{IU} / \mathrm{L}(1-9)$ \\
\hline Prolactin & $176 \mathrm{mU} / \mathrm{L}(86-324)$ & $139 \mathrm{mU} / \mathrm{L}(86-324)$ \\
\hline
\end{tabular}

FSH, follicle stimulating hormone; LH, luteinizing hormone. 
suggested as an etiology. ${ }^{7}$ Goth et al. reported increased level of VEGF in patients affected with POEMS syndrome. VEGF expression in blood vessels can be induced by hypoxia and VEGF plays a key role in endothelial cell proliferation, migration and angiogenesis. Over expression of the VEGF in patients with POEMS syndrome is thought to affect several endocrine axes due to disruption of local balance of angiogenic factors which are essential for regulation of hormonal secretion. ${ }^{8}$

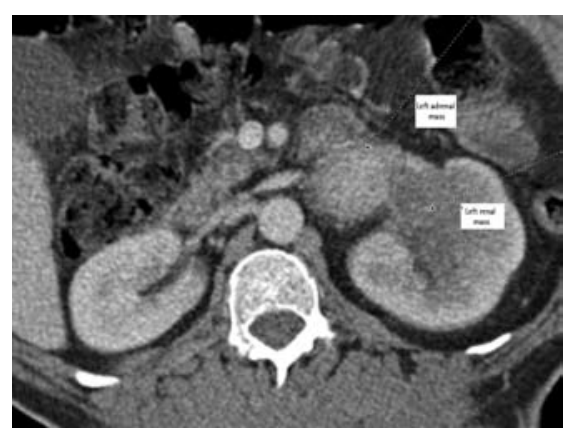

Figure 1. Adrenal and renal tumor on magnetic resonance imaging scan.

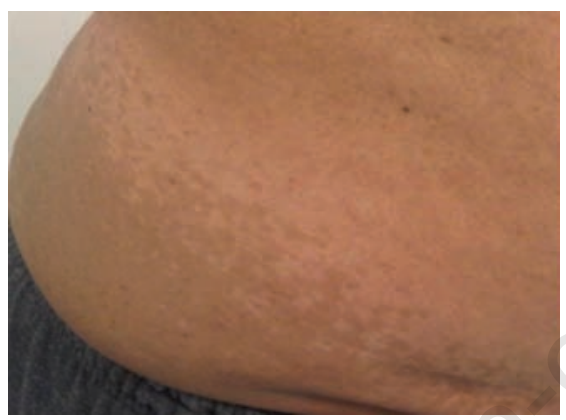

Figure 2. Hyperpigmented skin rash.

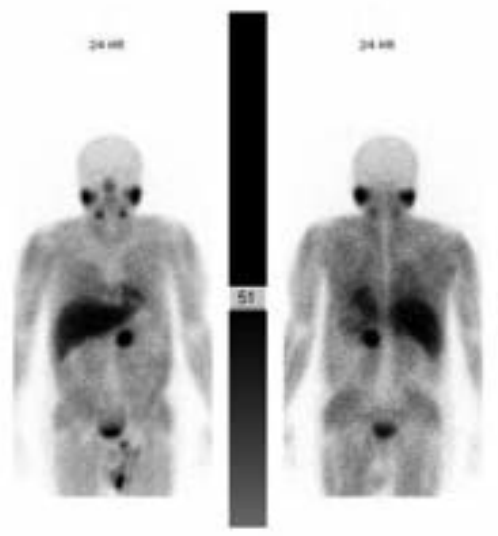

Figure 3. Positive MIBG scan for Pheochromocytoma.
High prevalence of diabetes and hypothyroidism in general population make these insufficient to meet minor criteria for POEMs syndrome but if these develop months to years after the onset of at least one other feature of POEMS syndrome then these could be considered as minor criteria. Hypogonadism is the commonest endocrine dysfunction reported in most case studies. In Mayo series published in 2007, $77 \%$ had low free testosterone and $61 \%$ had erectile dysfunction. ${ }^{2}$ In a Japanese case

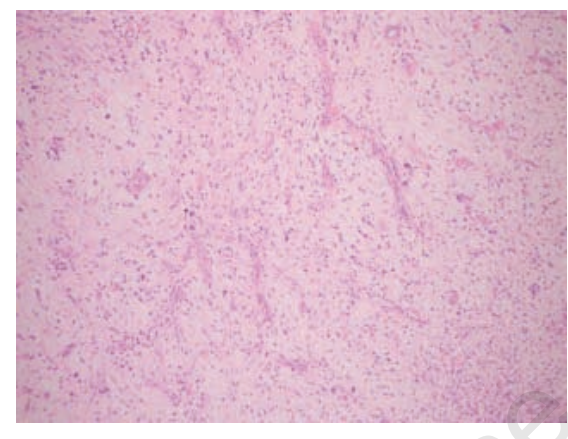

Figure 4. Myelofibroblastic tumor: the tumor has a patchy mixed inflammatory cell population which in some areas shows numerous plasma cells. The histological appearances support a diagnosis of myofibroblastic tumor.

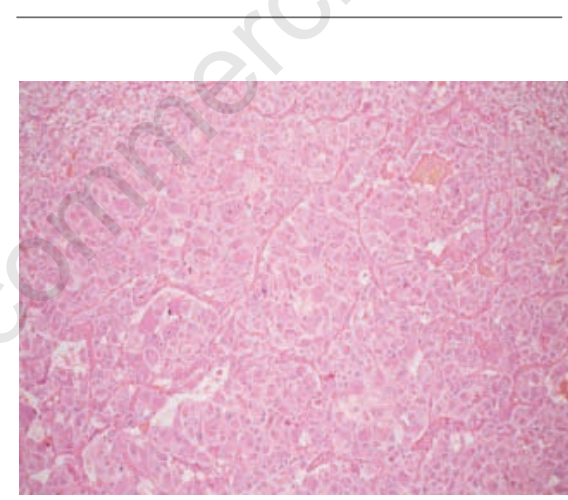

Figure 5. Pheochromocytoma with ganglioneuromatous areas.

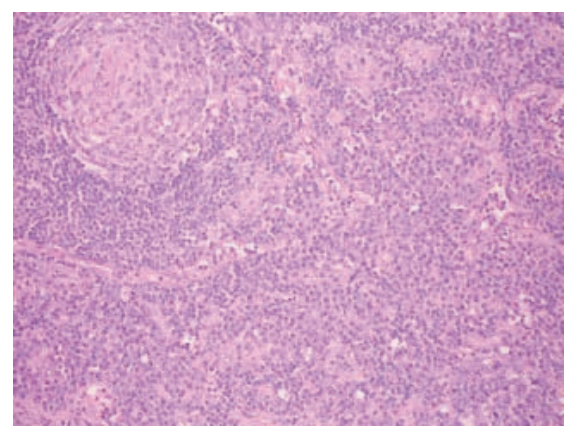

Figure 6. Castlemans disease of the plasma cell form. series, 39 of 50 men reported erectile dysfunction, ${ }^{9}$ whereas in the case series from France 9 of 19 men tested had hypogonadism. ${ }^{1}$ Hypogonadism is generally secondary in patients with POEMS syndrome and men may present with gynaecomastia in up to $40 \%$ of patients with hypogonadism.2,10 Hypogonadism may improve after treatment with corticosteroids in POEMS syndrome. ${ }^{11}$ Both of our patients had normal gonadotropin and testosterone level.

In Mayo series 10 of the 35 patients had elevated prolactin as compared to 4 out of 17 in the French series. The levels are usually mildly elevated as in our first case. Irregular periods and galactorrhea due to elevated prolactin in POEMS syndrome has been reported in women. Hypogonadism in patients with hyperprolactinemia persists even after normalising the prolactin. Treating hypothyroidism does not normalise prolactin in such cases. ${ }^{2}$

Involvement of thyroid axis is the second most common endocrine manifestation reported in POEMS syndrome. Hypothyroidism is the commonest presentation and it is usually mild. It is also essential rule out autoimmunity as a cause of thyroid illness. $58 \%$ of the patients in Mayo series had hypothyroidism with half of them being subclinical. In French series $45 \%$ of the cases were hypothyroid. Interestingly 2 out of the 10 patients from French series had secondary hypothyroidism. Antibody binding activity targeting endocrine tissue has been demonstrated in POEMS syndrome. ${ }^{12}$ Our first case developed a large goitre causing obstructive symptom and required thyroidectomy though he was clinically and biochemically euthyroid. Our second case developed primary hypothyroidism. This suggests the importance of regular endocrine follow up in patients with POEMS syndrome as manifestations may appear later and may be multiple.

Abnormal glucose metabolism is also a common manifestation in POEMS syndrome. 48\% of the patients in Mayo series had abnormal glucose metabolism. 16 had impaired glucose tolerance test (IGT) and 8 had diabetes mellitus (WHO criteria). In French series 40\% had abnormal glucose metabolism and similar result of 41\% were reported in Japanese series. Patients with diabetes have modest insulin requirements. ${ }^{1,2,9}$ Our first patient had IGT at presentation but after adrenalectomy his oral glucose tolerance has been normal.

Adrenal involvement in POEMS syndrome is infrequent and commonest adrenal disorder is adrenal insufficiency. Majority of the case reports have noted primary adrenal insufficiency. It is not clear if these patients were tested for adrenalautoantibodies. ${ }^{13}$ In Mayo series 6 of the 9 tested with short synacthen test had adrenal insufficiency. Pheocromocytoma in POEMS syndrome has been described in association with neurofibromato- 
sis 1 (NF-1) but not on its own. ${ }^{14}$ Our patient did not have NF-1. Parathyroid function has not been measured routinely in these patients. In Mayo series, 14 of the 51 who were tested had low calcium, 2 had high calcium, 12 patients out of 33 had high phosphorus. This data suggests that parathyroid dysfunction should be assessed in these patients. ${ }^{15}$ Pituitary involvement in patients with POEMS syndrome is rare. Patients with a non-functioning pituitary adenoma resulting in panhypopituitarism and acromegaly have been reported. ${ }^{16,17}$

\section{Conclusions}

Endocrinopathy is prevalent in POEMS syndrome. Diagnosis requires high index of suspicion and thorough investigations. These patients need long term monitoring. Management of POEMS syndrome should be multidisciplinary with involvement of endocrinologist, haematologist and neurologist.

\section{References}

1. Soubrier MJ, Dubost JJ, Sauvezie BJ. French Study Group on POEMS Syndrome. POEMS syndrome: a study of 25 cases and a review of the literature. Am $\mathrm{J}$ Med
1994;97:543-53.

2. Gandhi GY, Basu R, Dispenzieri A, et al. Endocrinopathy in POEMS syndrome: the Mayo Clinic experience. Mayo Clin Proc 2007;82:836-42

3. Bardwick PA, Zvaifler NJ, Gill GN, et al. Plasma cell dyscrasia with polyneuropathy, organomegaly, endocrinopathy, M protein, and skin changes: the POEMS syndrome. Report on two cases and a review of the literature. Medicine 1980;59:311-22.

4. Sasano T, Sakurai SI, Hara Y. Improvement in gonadotropin secretion after corticosteroid therapy in a case of POEMS syndrome. Endo J 1998;45:413-9.

5. Dispenzieri A, Kyle RA, Lacy MQ, et al. POEMS syndrome: definitions and longterm outcome. Blood 2003;101:2496-506.

6. Gherardi RK, Belec L, Soubrier M, et al. Overproduction of proinflammatory cytokines imbalanced by their antagonists in POEMS syndrome. Blood 1996;87:145865 .

7. Watanabe 0, Arimura K, Kitajima I, et al. Greatly raised vascular endothelial growth factor (VEGF) in POEMS syndrome. Lancet 1996;347:702.

8. Goth MI, Hubina E, Raptis S, et al. Physiological and pathological angiogenesis in the endocrine system. Microsc Res Tech 2003;60:98-106.

9. Nakanishi T, Sobue I, Toyokura Y, et al. The Crow-Fukase syndrome: a study of 102 cases in Japan. Neurology 1984;34:712-20.
10. Rodrigues P, Castedo JL, Rocha M, et al. Hypogonadotropic hypogonadism in POEMS syndrome - case report. Endocrine Abstracts 2010;22:227.

11. Sasano T, Sakurai SI, Hara Y. Improvement in gonadotropin secretion after corticosteroid therapy in a case of POEMS syndrome. Endo J 1998;45:413-9.

12. Reulecke M, Dumas M, Meier C. Specific antibody activity against neuroendocrine tissue in a case of POEMS syndrome with IgG gammopathy. Neurology 1988;38:6146.

13. Mauvais-Jarvis F, Bertherat J, Ravaud H, et al. [POEMS syndrome with primary adrenocortical insufficiency]. Presse Med 1998;27:15-7. [Article in French].

14. Stelfox HT, Stewart AK, Bailey D, Harrison D. Castleman's Disease in a 44-year-old male with neurofibromatosis and pheochromocytoma. Leuk Lymphoma 1997;27:551-6.

15. Cabezas-Agricola JM, Lado-Abeal JJ, Otero-Anton E, et al. Hypoparathyroidism in POEMS syndrome. Lancet 1996;347:7012.

16. Bruno C, Fleck JD, Cavaghan MK. Pituitary macroadenoma in a patient with POEMS syndrome in conjunction with Castleman disease.Endo Prac 2010;16:97-101.

17. Murphy PT, Ahmed N, Hassan HT. Chronic myeloid leukemia and acromegaly in POEMS syndrome. Leuk Res 2002;26:11357. 